\title{
GABRIEL CONROY E O ÚLTIMO MOCINHO DO MUNDO OCIDENTAL
}

\section{GABRIEL CONROY AND THE PLAYBOY OF THE WESTERN WORLD}

\author{
Mariana Luísa Figueiredo ${ }^{1}$
}

\begin{abstract}
Resumo: Yeats, Lady Gregory e Synge escrevem sobre o passado mitológico da Irlanda e enaltecem a vida rústica enquanto James Joyce (1882-1941) disseca o cotidiano das pessoas que vivem na tumultuada Dublin da virada do século. Os camponeses são o tema de The Playboy of the Western World (1907) por Synge, mas é um engano pensar que a peça do dramaturgo nacionalista e o episódio de sua estreia no Abbey Theater estejam completamente distanciados do retrato da burguesia irlandesa e do altivo e cosmopolita no Gabriel Conroy de "The Dead", o último e mais extenso conto da coletânea de histórias sobre os dublinenses, Dubliners (1904), incluído por Joyce na publicação quatro anos depois. O objetivo deste artigo é aproximar o conto "The Dead" e seu protagonista Gabriel Conroy da peça The Playboy of the Western World, e sua polêmica estreia, demonstrando como a peça reverbera de diferentes formas na escrita do conto de Joyce.
\end{abstract}

Palavras-chave: Synge, Joyce, nacionalismo, hibridismo.

Abstract: Yeats, Lady Gregory e Synge wrote about the mythological past of Ireland and eulogize the peasantry while Joyce dissected the daily life of people who lived in the chaotic turn-of-the-century Dublin. The peasants are the theme of The Playboy of The Western World (1907) by Synge, but it is not right to think that the play and the episode concerning its début in the Abbey Theatre are completely apart from the portrayal of Irish middle-class and the arrogant, cosmopolitan Gabriel Conroy from "The Dead", the last and longest text of the collection of short stories about people from Dublin, Dubliners (1904), which was added by Joyce to the book four years later. This article aims to connect "The Dead" and its main character Gabriel Conroy to the play The Playboy of The Western

\footnotetext{
${ }^{1}$ Mestre em Estudos Literários pela Universidade Federal de Ouro Preto. Contato: teacher.mariana@hotmail.com
} 


\section{Revista InterteXto / ISSN: 1981-0601}

v. 8 , n. 1 (2015)

World and its polemical début demonstrating how the play reverberates in different forms in the writing of Joyce's short story.

Key words: Synge, Joyce, nationalism, hybridism.

James Joyce (1882-1941) é conhecido como um dos mais inovadores escritores do século XX. Autor de importantes obras como The Portrait of The Artist As a Young Man (1916), Ulysses (1922) e Finnegans Wake (1939), Joyce atinge o ápice do seu rompimento com várias tradições estéticas da escrita com seu último romance, que apesar de ser considerado demasiadamente complexo por alguns críticos, torna-se um grande marco para a literatura ocidental.

O uso intenso de fluxo de consciência juntamente com a mistura de regionalismos da sua própria experiência com os substratos psicológicos da experiência humana em geral e o seu crescente interesse pela força criativa da linguagem, fazem com que este autor consiga consolidar o seu nome em meio a outros escritores irlandeses de grande talento como Bernard Shaw, Synge e Yeats.

Em "The Dead", o último e mais extenso conto da coletânea de histórias sobre os dublinenses, incluído no livro Dubliners (1904), quatro anos depois, em 1908, acompanhamos o personagem Gabriel Conroy, que vai a uma festa na casa das tias solteironas, duas velhas professoras de música que têm nele o sobrinho preferido. Gabriel tenta inutilmente se demonstrar como bem-sucedido e se manter altivo ao longo da festa, mas se vê capturado em uma série de frustrações que corroem o seu ego, advindas de dolorosas interações com mulheres.

A primeira delas acontece logo em sua chegada. Ao ser recebido pela criada, Lily. Gabriel tenta ser cordial iniciando uma conversa, e ao insinuar que ela se casaria em breve, é surpreendido com uma "má-resposta" da criada que diz que "os homens de hoje em dia só querem saber de palavrório e de se aproveitar das meninas" (JOYCE, 2012, p. 171).

Em seguida, antes do jantar oferecido pelas tias, no qual ele fará um discurso, dança com Molly Ivors, uma senhorita nacionalista que o golpeia com sucedidas perguntas provocativas sobre seu "posicionamento político". 


\section{Revista InterteXto / ISSN: 1981-0601}

v. 8 , n. 1 (2015)

A última das interações falhas se dá com sua esposa, Gretta, que, tanto na carruagem que os levaria para o hotel quanto no momento em que já estão a sós no quarto, responde com frieza e rejeição às suas investidas sexuais.

No quarto de hotel, Gabriel tem uma revelação sobre o passado da esposa e a maneira como ele reage é um dos pontos chaves da história. Ao saber que ela estivera pensando em um amor do passado, o falecido Michael Furey, Gabriel passa de uma reflexão sobre o seu relacionamento com Gretta para uma autoanálise que alcança um panorama bem mais amplo, o de sua própria existência. O conto permite que acompanhemos todo o processo de desconstrução da identidade de Gabriel Conroy.

Joyce captura com perícia as variações de humor e as diferentes atmosferas de uma longa festa de feriado. As provações que o autor prepara para os seus personagens são tão devastadora que esta anual dance se tornaria excepcional. Gabriel entra em uma cena complexa: tipos diferentes de pessoas, oriundas de diferentes classes; estranhos, conhecidos, amigos e familiares, e a cada momento é exigido de Gabriel comportamentos distintos, no entanto, o Senhor Conroy não é exatamente do tipo de homem que se adapta ou adequa com facilidade.

O jantar oferecido pelas Irmãs Morkan, precede a festa da epifania, na qual se celebra a revelação da natureza divina de Jesus Cristo. Em termos cristãos, a palavra epifania significa a manifestação da presença de Deus na terra.

Friedrich (1965) chama a atenção para o significado dos feriados, ele afirma que "há necessidade de uma Páscoa no Natal coberto de neve de Joyce, um feriado implicando no outro. Enquanto o espírito de Michael Furey levanta da sepultura para caminhar a subjugar os sobreviventes, os mortos-vivos aguardam a ressurreição". ${ }^{2}$

Os mortos-vivos em questão são os habitantes de Dublin que, ao contrário de Gabriel Conroy, que em determinado momento percebe a influência das forças opressivas da cidade, permanecem capturados em suas autoconsciências paralíticas. A epifania seria o instrumento capaz de "ressuscitá-los".

\footnotetext{
${ }^{2}$ FRIEDRICH 1965. p. 425. There is need for Easter in Joyce's snowbound Christmas, the one implying the other. While the spirit of Michael Furey has risen from the grave to walk overpowering the survivors, the living dead remain to be resurrected. Todas as citações, exceto as com indicação bibliográfica, foram traduzidas por mim do inglês para o português.
} 


\section{Revista InterteXto / ISSN: 1981-0601}

\section{v. 8, n. 1 (2015)}

No entanto, ao falar de epifania, não mais estamos falando de uma manifestação divina literal, como o significado de origem eclesiástica do termo. Joyce se apropria da palavras epifania para designar um estado mental secular no qual há uma súbita manifestação espiritual ou um momento de iluminação que leva a uma revelação quando se observa alguma banalidade.

Em "Stephen Hero", rascunho de A Portrait of The Artist as a Young Man, publicado postumamente em 1944, Joyce redesenha a definição do termo ao escrever que as epifanias correspondem a uma manifestação súbita, quer na vulgaridade do discurso ou do gesto, ou em uma fase memorável da própria mente. "Sua alma, seu quê próprio salta para nós das vestes de sua aparência. A alma do objeto mais comum, cuja estrutura está tão ajustada, parece-nos radiosa. O objeto realiza sua epifania". (JOYCE, 1963, p.218). ${ }^{3}$

Essa noção de epifania, adaptada por Joyce, se torna o termo chave na Literatura Ocidental para a descrição desse momento de iluminação súbita advindo da observação de um objeto ou cena comum. Ela é central na escrita joyciana e abarca todas as suas obras. Em Dubliners, os personagens experienciam grandes ou pequenas revelações em suas vidas cotidianas. Estas revelações permitem que eles entendam melhor suas existências, impregnadas de melancolia e rotinas fastidiosas, para as quais eles resignadamente retornam, alimentando ainda mais as suas frustrações.

As provações que o autor prepara para os seus personagens são tão devastadora que esta anual dance se tornaria excepcional. Gabriel entra em uma cena complexa: tipos diferentes de pessoas, oriundas de diferentes classes; estranhos, conhecidos, amigos e familiares, cada momento exigindo de Gabriel comportamentos distintos, mas ele não é exatamente aquele que se adapta com facilidade.

O senso de educação superior de Gabriel juntamente com sua debilitada percepção de si aponta, segundo Schwarz (1994), não somente a semelhança de Gabriel com o próprio autor, mas também uma deficiente autoconsciência típica do modernismo, a anestesia dos sentimentos promovida pelo estudo. Para Schwarz, a figura patética que Gabriel é representaria para Joyce uma versão do que ele temia se transformar caso

\footnotetext{
3 JOYCE, 1963, p. 218. This is the moment which I call epiphany. First we recognise that the object is one integral thing, then we recognise that it is an organised composite structure, a thing in fact: finally, when the relation of the parts is exquisite, when the parts are adjusted to the special point, we recognise that it is that thing which it is. Its soul, its whatness, leaps to us from the vestment of its appearance. The soul of the commonest object, the structure of which is so adjusted, seems to us radiant. The object achieves its epiphany.
} 


\section{Revista InterteXto / ISSN: 1981-0601}

v. 8 , n. 1 (2015)

continuasse influenciado pelas forças abortivas da Irlanda, um burguês que vive em cliché, exclamando "Cá estou, infalível como o correio!" 4 , usando galochas porque todos as usam no continente, escrevendo para um jornal conservador e de menor importância e conseguindo seu sustento lecionando. A ambivalente relação Irlanda/Europa é percebida nesse aspecto do personagem que falha tanto em se provar irlandês quanto em se afirmar como europeu.

A problematização da nacionalidade híbrida Europa/Irlanda através do personagem Gabriel Conroy possivelmente se dá em decorrência da identidade nacional híbrida e conflituosa do próprio Joyce, que conseguia tampouco aceitar sua nacionalidade quanto bani-la.

Joyce escolhe caracterizar a Irlanda de uma forma muito distinta da que faziam Yeats e Synge. Enquanto os nacionalistas retomavam os mitos de um passado glorioso, "The Dead" entranhava-se na vida de um burguês da classe média irlandesa. Essa escolha é apontada por Eagleton (2005) como um desafio lançado por Joyce à Irlanda mitológica de seus colegas ${ }^{5}$. No entanto, há leituras que nos permitem observar que 0 escritor estava mais próximo da vertente nacionalista do que se imaginava, a começar pelo estudo do personagem Gabriel Conroy e engana-se quem pensa que a história de Dubliners passaria ilesa à política nacionalista que permeava Joyce nos anos de escrita da coletânea de contos.

Em Janeiro de 1907, Synge escreve no prefácio de The Playboy of the Western World que:

$\mathrm{Na}$ Irlanda, por alguns anos mais, temos um imaginário popular que é ardente e magnificente, e terno; por isso aqueles de nós que desejam escrever começam com uma chance que não é dada a escritores em locais onde a primavera da vida local

\footnotetext{
4 JOYCE, 1994, p.120. Here I am as right as the mail.

${ }^{5}$ EAGLETON, 2005, p.284 By depicting lower-middle-class life in Dublin, he was among other things challenging the mythological Ireland of Yeats and his colleagues, who wrote of ancient warriors and mystic twilights rather than middleaged cuckolds squatting glumly on the lavatory. Joyce priest-ridden colonial capital, and doing so placed it permanently on the global map.
} 


\section{Revista InterteXto / ISSN: 1981-0601}

\section{v. 8, n. 1 (2015)}

foi esquecida, e a colheita é apenas uma memória, e a palha foi transformada em tijolos. (SYNGE, 1993, p.6). ${ }^{6}$

Enquanto John Millington Synge (1871-1909) mergulha no cotidiano popular das Ilhas Aran, James Joyce segue o caminho oposto, deixando a Irlanda para um longo autoexílio em outros países da Europa. No entanto, ainda que o escritor esteja "desafiando a Irlanda mitológica de Yeats e seus colegas ao escolher retratar a burguesia Irlandesa"7 a Irlanda e o autor se apresentam indivisíveis na experiência de ler um dos seus livros de uma forma um pouco mais plena. As alusões de Joyce trazem o peso de eras passadas e contextos históricos para o íntimo de nossa leitura. Na coletânea de contos Dubliners (1904), a cidade de Dublin é o símbolo máximo das forças opressivas, cúmplices e catalisadoras da paralisia dos personagens que tentam se libertar material, artística ou espiritualmente deste ambiente.

Se no prefácio para sua peça, Synge se referia à temática campestre (peasantry) em detrimento de histórias sobre a cidade, então, certamente Joyce transformou "a palha em tijolos" uma vez que suas histórias falam de pessoas profundamente influenciadas por suas rotinas urbanas.

No entanto, isto não fez com que a "primavera da vida local" fosse esquecida, na verdade, na escrita joyciana, ela se transmuta um fantasma insuperável. A história de "The Dead" é aparentemente distante da contada por Synge em The Playboy of the Western World (1907) que narra os feitos de Christy Manhon: o protagonista Christy Mahon chega à taverna do Flaherty e diz que matou seu pai e é um fugitivo. Flaherty elogia Christy por seu ímpeto e o convida para trabalhar para ele, estimulado por sua filha e garçonete da taverna, Pegeen. Ela apaixona-se por Christy, mesmo sendo noiva de um rapaz chamado Shawn.

Logo, a notícia das façanhas de Christy, cada vez mais conduzido por seus ouvintes a contá-las com eloquência, se espalha por toda a cidade que o vê como uma espécie de herói. Várias mulheres tentam seduzi-lo, dentre elas a viúva Quin, a mando de Shawn.

\footnotetext{
${ }^{6}$ SYNGE, 1993, p.6. In Ireland, for a few years more, we have a popular imagination that is fiery and magnificent, and tender; so those of us who wish to write start with a chance that is not given to writers in places where the springtime of local life has been forgotten, and the harvest is a memory only, and the straw has been turned into bricks.

${ }^{7}$ EAGLETON(2005) p. 284. By depicting lower-middle-class life in Dublin, he [Joyce] was among other things challenging the mytological Ireland of Yeats and his collegues.
} 


\section{Revista InterteXto / ISSN: 1981-0601}

\section{v. 8, n. 1 (2015)}

Porém, Christy havia somente ferido seu pai, Mahon, e eventualmente ele o segue até a taberna. Quando os habitantes da cidade percebem que o pai de Christy está vivo, todos, inclusive Pegeen, o insultam por ser um mentiroso e um covarde.

Para que recupere o amor de Pegeen e o prestígio da cidade, Christy ataca seu pai novamente. Desta vez, o velho Mahon aparenta estar realmente morto, mas ao invés de elogiar Christy, os habitantes da cidade, liderados pela garçonete da taberna, decidem enforcá-lo para evitar serem punidos como cúmplices do patricídio.

A vida de Christy é salva quando seu pai, espancado e ensanguentado, rasteja de volta para a cena, depois de ter sobrevivido, contra todas as expectativas, ao segundo ataque do filho. Os dois deixam a cidade para vagar pelo mundo, e Shawn sugere que ele e Pegeen se casem em breve, mas ela se recusa. A garçonete afirma ter se arrependido por ter traído e abandonado Christy, segundo ela, o último mocinho do mundo ocidental.

Dois contrastes entre Christy e os camponeses são apontados por Diehl (2001). autor destaca que o caráter dubio de Christy contrastado com a honestidade simples dos camponeses e a artificialidade do protagonista posta em cheque pela autenticidade dos moradores do vilarejo. Segundo Diehl, ainda que os personagens não sejam os mais virtuosos, eles não são deliberadamente falsos.

Em sua estreia no Abbey Theatre, a peça The Playboy of The Western World foi recebida com ódio e fúria pelos nacionalistas irlandeses por, segundo eles, "denegrir um passado glorioso da Irlanda". Ela incitou inúmeros conflitos em parte pela obra não romantizar e ser satírica no tratamento do Irish peasantry - considerado sacrossanto por muitos nacionalistas- a "reconstrução do dialeto camponês" feita por Synge provocou inúmeras controvérsias que continuaram ainda após a morte prematura do autor.

É importante destacar a importância do lugar onde a peça de Synge foi recebida de maneira hostil. Nos seus primeiros anos, o Abbey Theatre, ou National Theatre of Ireland, esteve estritamente relacionado ao Movimento Dramático Irlandês. Através de um teatro nacional, eram apresentadas produções escritas em inglês e irlandês, escritas por dramaturgos da Irlanda ou inspiradas em motivos irlandenses.

Synge, apontado pelo artigo de Hirsch (1991), junto de nomes como o de Yeats, Lady Gregory, como um dos principais responsáveis por tornar a figura do camponês um 
símbolo central para a construção de um discurso cultural irlandês durante a Renascença Céltica, escreve um texto inundado de dialetismos do irlandês, para Diehl uma evidência do senso de Irishness dos camponeses:

Através dos camponeses, Synge representa mimeticamente um senso estável, coerente de identidade irlandesa, evidenciado mais claramente no uso feito pelo dramaturgo do folclore popular e do dialeto camponês (...) o perene desejo que Synge possuía de restaurar e preservar os textos folclórico-culturais do gaélico-irlandês dos camponeses necessariamente insere seu trabalho dentro de um esforço nacionalista. ${ }^{8}$

A forma com Christy é conduzido em sua oratória, tal como referências ao episódio acerca da estreia de The Playboy of the Western World reverberam na história escrita por Joyce no conto "The Dead" e na construção do personagem Gabriel Conroy. Ao passo que Synge abraçava a Irlanda como inspiração, Joyce sofria a tensão do hibridismo Irlanda/Europa no cerne da construção de sua própria identidade, tanto em sua vida pessoal quanto em sua carreira como escritor. Nesse processo vivido por Joyce, o episódio que envolve Synge e os nacionalistas funciona como uma espécie marco sobre a dificuldade do escritor em ignorar o nacionalismo irlandês em prol de uma literatura politicamente neutra.

Gabriel em "The Dead" tenta incansavelmente se provar bem sucedido e é, com a mesma intensidade, frustrado em suas investidas. Apesar da sua epifania final, a solução dos conflitos travados por ele não se desliga do tema da paralisia. Gabriel é completamente surpreendido pelas situações humilhantes que passa e se demonstra, no entanto, incapaz de "corrigi-las" satisfatoriamente.

Os trocados que ele oferece a Lily após o diálogo desagradável não suavizam a situação vivida com a criada, a Senhorita Ivors deixa a festa sem que ele responda aos insultos que Ihes são feitos e Gretta adormece aos prantos, sozinha, na cama do hotel.

Backus (2001) lembra que o fracasso de Gabriel em dar dinheiro a Lily funciona como uma antecipação de seu fracasso em se esquivar dos questionamentos da Senhorita Ivors; além disso, reflete e critica a fraqueza de uma estratégia política baseada na evasão e nos rodeios.

\footnotetext{
${ }^{8}$ DIEHL 2001, p. 105. Through the villagers, Synge mimetically represents a stable, coherent sense of Irish identity, evidenced most clearly in the playwright's use of folk history and peasant dialect (...) Synge's assiduous desire "to restore and preserve the folk-cultural texts of the Gaelic-Irish peasanty necessarily locates his work within a nationalist endeavor.
} 


\section{Revista InterteXto / ISSN: 1981-0601}

\section{v. 8, n. 1 (2015)}

Durante a dança que precede o jantar na festa das senhoras Morkan, a Senhorita Ivors interroga Gabriel incessante e agressivamente. Os dedos quentes dela que agarram a mão dele para a dança são uma boa metáfora física para o vigor energético da conversa. A nacionalista o ofende por ele se recusar a ir para as Ilhas Aran, e o acusa de "partidário dos britânicos" (West Briton) por não ser "nacionalista" em sua escrita no jornal, ao passo que Gabriel tenta inutilmente defender sua postura neutra em relação ao nacionalismo Irlandês, dizendo que não vê nada de político em sua coluna literária e que viajava para outros lugares senão a Irlanda para aprender línguas e mudar de ares.

Porém, a tentativa de neutralidade política buscada por Gabriel ao se justificar por não escrever sobre política em sua coluna e por gostar de viajar para outros países, não é suficientemente acatada pela Senhorita Ivors, que, após dizer que é a Irlanda a única nação que ele deveria visitar e o irlandês a única língua que ele deveria aprender, acaba por repetir o insulto "partidário dos britânicos", dessa vez exclamado como ofensa direta e não como a pergunta acusatória e insinuante do início da conversa.

O embate entre a Senhorita Ivors e Gabriel sobre o destino de viagem é, para Ellmann (1958), um eco do episódio da briga em Dublin sobre The Playboy of Western World de Synge. Segundo Ellmann, o dramaturgo haveria aceitado a sugestão de Yeats, que Joyce havia rejeitado, de achar a sua inspiração no folclore Irlandês, e teria ido justamente para as Ilhas Aran. Contudo, o "elogio" feito por Synge através da temática peasant resgatada em sua peça, teve uma repercussão inesperada e o episódio se tornou para Joyce um marco de como a arte encontra dificuldades em se manter politicamente neutra - em especial ao tratar temáticas nacionalistas. Neste contexto, a dificuldade de se esquivar das acusações de Molly se equipara aos ataques hostis vividos pelo dramaturgo Synge por sua comédia.

Em seu artigo, Kiberd relembra que St. John Ervine chama Synge de "um falsificador da fala do camponês". 9 "Esta notória acusação foi respondida por outro importante escritor irlandês, Yeats, com os dizeres "talvez nenhum camponês irlandês tenha tido aquele exato ritmo em sua voz, mas certamente se o Sr. Synge tivesse nascido um homem do campo, ele teria falado assim." 10

\footnotetext{
${ }^{9}$ KIBBERD. 1979, p. 59. A faker of peasant speech.

${ }^{10}$ W. B YEATS, 'Preface to The Well of the Saints' , Essays and Introduction (London, 1961), p. 300) em KIBERD, 1979. p.59. "Perhaps no Irish countryman had ever that exact rhytm in his voice, but certainly if Mr. Synge had been born a countryman, he would have spoken like that."
} 


\section{Revista InterteXto / ISSN: 1981-0601}

\section{v. 8, n. 1 (2015)}

Porém o maior incômodo causado nos nacionalistas pela estreia da peça de Synge no Abbey Theatre foi a diminuição cômica do passado heroico Irlandês. Na peça de Synge, há uma evidente sátira da violência como uma característica positiva, por exemplo, quando o herói, se recusa a matar o pai ele é fortemente repreendido e chamado de covarde.

O efeito cômico em "The Dead" no episódio do embate entre Molly e Gabriel não está só na incapacidade de Conroy em se manter neutro em relação às políticas nacionalistas, está também na natureza mimética do termo que a Senhorita Ivors usa como mockery: West-Briton, nascido do discurso de um líder nacionalista, pejorativo em relação aos irlandeses percebidos pelos demais conterrâneos como exacerbadamente anglicanos. É pejorativo exatamente por colocar o West-Briton em um explícito nãopertencer, a ofensa é equivalente a um "falso-irlandês" ou até mesmo "irlandês de araque". No termo, temos que não se é britânico, nem irlandês, nem anglófilo, mas ocupase um lugar de "partidário", isto é, adepto, favorável, e não de "membro", componente, parte integrante.

A situação desconfortável vivida com a Senhorita Ivors imediatamente irrompe em um conflito de Gabriel e sua mãe sobre o seu casamento com Gretta. ～Ellmann （1958) aponta que a vergonha que Gabriel sente da origem de sua esposa, evidenciado pela resposta "a família dela é", quando Molly o provoca perguntando se sua esposa não era de Connacht, e por não conseguir desapegar do comentário de sua mãe sobre Gretta ser uma "beleza campestre", se relacionam com a dificuldade de aceitar o West e a Irlanda nacionalista. É importante ressaltar que neste conflito com Molly, Gabriel deixa claro que a sua língua não é o Irish, comentário que suporta a ideia de que Gabriel tenta apagar as suas associações com o Oeste, simbolizadas também pelas Ilhas Aran e pela conexão com o nacionalismo feito por Synge.

O momento em que Gabriel é capturado pelas lembranças de sua mãe ao confrontar a nacionalista Senhorita Ivors é descrito por Ingersoll em Backus (2001) como um vínculo duplo explícito. Para o autor, o fato de Gabriel não conseguir se emancipar de sua mãe e de Gretta é uma metáfora política. Ele afirma que "nenhum homem irlandês 


\section{Revista InterteXto / ISSN: 1981-0601}

\section{v. 8, n. 1 (2015)}

tem o potencial para se tornar plenamente 'másculo', porque o poder está todo no Oriente [Europa]". ${ }^{11}$

Sobre esse mesmo episódio, Backus acrescenta à afirmação de Ingersoll a perspectiva da relação entre gêneros. A autora afirma que se casar com Gretta sem a benção de sua mãe é uma estratégia utilizada por Gabriel para manter uma identidade masculina autônoma em face da crescente feminilização cultural irlandesa e legitimar a sua associação ao East e rejeição ao West. Entretanto, paradoxalmente, essa estratégia deixaria entrever sua contínua subordinação à sua mãe. Segundo Norris, "a voz narrativa tem uma agenda burguesa: produzir uma imagem lisonjeira de vida da classe média irlandesa, cujo centro de segurança e confiabilidade é Gabriel Conroy, patriarca de uma família de mulheres". (NORIS, 1994, p. 193)

A posição social de Gabriel é ainda colocada em contraste com os outros personagens masculinos, retratados como bêbados e fracassados, das outras histórias de Dubliners, os quais, segundo a autora, são o oposto do homem instruído, culto e cosmopolita que é Gabriel em "The Dead”. O senso de educação superior de Gabriel juntamente com sua debilitada percepção de si aponta, segundo Schwarz (1994), não somente a semelhança de Gabriel com o próprio autor, mas também uma deficiente autoconsciência típica do modernismo, a anestesia dos sentimentos promovida pelo estudo.

Mas não é somente na caracterização cosmopolita de Gabriel em contraste com o peasant de Yeats e Synge que encontramos reverberações da relação do autor com a corrente nacionalista de seus contemporâneos. A canção For He's a Jolly Good Fellow é praticamente tão popular quanto o Parabéns para você no Reino Unido, e, é cantada para as senhoras Morkan em um belo coro após o pomposo discurso de jantar feito por Gabriel e assume outro aspecto além de predizer a morte iminente das anfitriãs as quais atribuir adjetivos como jolly gay (feliz, alegre, jovial) é sem dúvida um exagero, ou uma lie (mentira) por parte dos convidados. A canção poderia igualmente estar falando de Christy de forma satírica, em especial pela ênfase para a parte da canção que diz "unless he tells a lie" (JOYCE, 1991, p.140) afinal, em The Playboy of The Western World, não era Christy

\footnotetext{
${ }^{11}$ BACKUS, 2001, p.125. No Irishman has the potential to become fully 'male', because the power is all in the East [Europe]
} 


\section{Revista InterteXto / ISSN: 1981-0601}

v. 8 , n. 1 (2015)

um herói até que a mentira sobre matar seu pai foi descoberta? Ou poderia a canção até mesmo estar aludindo às duras críticas recebidas por Synge por ter utilizado um dialeto camponês não necessariamente fiel ao falado nas ilhas Aran?

No ensaio Aran: a descoberta de um dramaturgo, Lima (1997) destaca que durante os cinco anos vividos nas Ilhas Aran, entre 1898 e 1902, Synge descobriu um tipo de irlandês peculiar, que chama a atenção por seu empreendedorismo e sua força trabalhadora que Synge explora na temática de suas peças. É curioso notar que após esta canção cantada no "The Dead", conhecemos a história do cavalo Johnny, encenada por Gabriel para o deleite dos convidados da festa. Ele conta como o avô, homem simples, trabalhador, colocou seus trajes de gala e saiu com seu cavalo para assistir um desfile militar junto com a nata da sociedade irlandesa. Porém, Johnny, o cavalo do avô, de tão acostumado ao trabalho no moinho pôs se a rodear a estátua do Rei Guilherme durante o desfile. A história é irônica ao passo que Gabriel, ao caçoar da rusticidade do avô e do cavalo, não percebia que ele mesmo estava enredado em um contínuo de repetições que não se diferenciava do cavalo que girava em círculos. A intenção de Synge em preservar o dialeto camponês em The Playboy of the Western World também o aproxima da história do cavalo Johnny. Tal qual o avô e o cavalo que falham na investida cosmopolita, o dialeto camponês reproduzido por Synge soa inadequado para os nacionalistas.

O nome Gabriel Conroy é também o título de um romance de 1876 escrito por Bret Harte. Harte é aproximado de Synge nas duras críticas sobre sua relação com o dialeto específico que tenta representar, no caso, não o irlandês campestre das peças de Synge, mas o inglês falado pelos mineradores, que até mesmo Twain clamou não existir senão na cabeça do escritor ${ }^{12}$. Eagleton (2005) nos chama atenção para como um escritor como Joyce, vivia uma consciência linguística que era diferenciada graças ao pano de fundo da linguagem que surge no contexto colonialista:

Em uma nação onde você pode deslocar-se entre vários tipos de discurso (irlandês, inglês, Hiberno-ingleses, escoceses do Ulster e assim por diante), os escritores eram mais propensos a ter consciência da natureza

\footnotetext{
${ }^{12}$ KRAUTH, Leland. Mark Twain \& Company: Six Literary Relations. University of Georgia Press, 2003.
} 


\section{Revista InterteXto / ISSN: 1981-0601}

\section{v. 8, n. 1 (2015)}

problemática da linguagem do que aqueles que, como os ingleses, poderia levar a sua chamada língua materna, como totalmente garantida. ${ }^{13}$

A afirmação de Eagleton parece igualmente verdadeira quando retomamos o trato dado à linguagem por autores irlandeses nacionalistas como Synge.

Mas voltemos ao "The Dead": Michael Furey, o amor do passado que Gretta relembra é uma representação do West enquanto Gabriel é uma representação do East da Irlanda, ou, em outros termos, o peasant e o cosmopolita.

O jovem morto aos dezenove anos pelo ímpeto de sua paixão por Gretta, se contrastado com Gabriel, faz com que o rapaz assuma o papel de um herói romântico. A investida de Michael contra a chuva, já com a saúde fragilizada, é marcada pela fatalidade de seu ato. Michael é dotado de uma hipersensibilidade, capaz de movê-lo totalmente pela intuição e pelo amor em detrimento da racionalidade. Michael também simboliza a vida simples de um jovem trabalhador que passeava com Gretta em Galway, "um rapaz no gasômetro" (JOYCE, 2012, p. 212), repetia Gabriel, para si mesmo. Gabriel, ao contrário de Michael, era, até então, cego ao comodismo e à paralisia que o dominava, preso a uma vida burguesa e até mesmo clownesca. Ao ver-se subitamente surpreendido por essa autoconsciência, Gabriel reflete sobre sua condição:

Sentiu-se invadido por uma consciência vergonhosa em relação a si próprio. Viu-se como uma figura ridícula, como o estafeta das tias, como um sentimentalista nervoso e bem-intencionado que discursava para o vulgo e idealizava as próprias luxúrias farsescas, como o pobre sujeito patético que tinha vislumbrado no espelho. ${ }^{14}$

\footnotetext{
${ }^{13}$ EAGLETON, 2005, p. 287. In a nation where you could move between several kinds of speech (Irish, English, Hiberno-English, Ulster Scots and so on), writers were more likely to be aware of the problematic nature of language than those who, like the English, could take their so-called mother tongue largely for granted.

${ }^{14}$ JOYCE, 1994, p.56 A shameful consciousness of his own person assailed him. He saw himself as a ludicrous figure, acting as a pennyboy for his aunts, a nervous well-meaning sentimentalist, orating to vulgarians and idealizing his own clownish lusts, the pitiable fatuous fellow he had caught a glimpse of in the mirror.
} 


\section{Revista InterteXto / ISSN: 1981-0601}

\section{v. 8, n. 1 (2015)}

Não coincidentemente, a luz da rua de Dublin que se projeta de um poste à janela do quarto de hotel onde os dois se hospedam é fantasmagórica. Ela precede a aparição de um fantasma, não literal como em A Christmas Carol de Charles Dickens, mas capaz de fazer Gabriel refletir sobre a morte, eminente para Tia Julia, não tardia para todos, e chegar à conclusão de que "é melhor passar com bravura ao outro mundo, em meio a glória de uma paixão, do que esmaecer e murchar com as agruras da idade". Mas o fantasma de Furey também simboliza a Irlanda nacionalista de Synge.

A palavra pennyboy, sendo traduzido como "estafeta", mensageiro postal, nos remete a The Playboy of the Western World, já que o original se refere à penny pot-boy, garçom em uma espelunca, e é o emprego oferecido à Christy. ${ }^{15}$

O conto não explicita qual será a atitude de Gabriel após o vislumbre de sua condição, porém, a possibilidade de mudança é sinalizada por Joyce não só através da conclusão de Gabriel, mas também pela simbologia dos nomes Michael, anjo da salvação, o guerreiro que brada a lâmina e comanda o exército contra as forças de Satã; e Gabriel, anjo da anunciação e da benevolência.

Nas palavras de Schwarz (1994), quando lemos Dubliners respondemos de várias formas à leitura, porém, os aspectos dominantes da paralisia estão claros no final de "The Dead":

Para o último protagonista de uma série de histórias sobre paralisia moral na Irlanda, a autoconsciência paralítica de Gabriel e sua incapacidade de se conectar com Gretta Ihe conferem importância como representante da falta de vontade, desmantelamento da família, e inadequação sexual que, juntamente com (e talvez como resultado de) o catolicismo e o imperialismo inglês, estão paralisando Irlanda. Mas como uma figura peculiar que percebeu suas limitações como amante e homem e sente simpatia por sua esposa, Gabriel é interessante e significativo, porque ele tem o potencial de crescimento e transformação. ${ }^{16}$

\footnotetext{
${ }^{15} \mathrm{He}[$ Gabriel] saw himself as a ludricous figure, acting as a pennyboy for his aunts(...) Joyce, 1994,p.56.

Michael (with deference). Would you think well to stop here and be potboy, mister honey, if we gave you good wages, and didn't destroy you with the weight of work? (Synge, 1993, p.12)

${ }^{16}$ SCHWARZ,1994, p. 121. For as the last protagonist in a series of stories about moral paralysis in, Ireland, Gabriel's paralytic selfconsciousness and his inability to connect with Gretta give him significance as a representative of the failure of will, breakdown of family, and sexual inadequacy that, along with (and perhaps as a result of) Catholicism and English imperialism, are paralyzing Ireland. But as a particularized figure who has realized his limitations as a lover and a man
} 


\section{Revista InterteXto / ISSN: 1981-0601}

\section{v. 8, n. 1 (2015)}

Como aponta Schwarz, Gabriel é um sujeito interessante para que a mudança possa ser operada e a epifania seria o suficiente para impulsioná-lo a se libertar das forças abortivas de Dublin. Na verdade, não só se libertar da cidade, mas também reconfigurar a sua relação com a própria Irlanda.

$\mathrm{Na}$ passagem final do conto, Gabriel afirma que é chegado o momento de sua jornada rumo ao Oeste. Mas o que encontramos no oeste, além da simbologia da inevitável morte e decadência? À Oeste estão as Ilhas Aran, mencionadas por Molly Ivors. Também está Galway, onde Gretta e Nora (esposa de Joyce) nasceram. Está o cemitério solitário onde Michael Furey repousa. Oeste é o lugar que simbolicamente representaria uma Irlanda mais nacionalista e rústica na mente de Joyce/Gabriel. Vários aspectos conectam na mente de Gabriel o oeste da Irlanda com um doloroso e sombrio "primitivismo", um pedaço do país que ainda resiste a se voltar para o continente, como exemplificam Ellmann (1958) e Norris (2001), acerca da relação de Gabriel e a origem de sua esposa Gretta, mas a mudança de tom no monólogo de Gabriel, que indica também uma mudança de compreensão da realidade, não insere o Oeste em um novo contexto?

Desta forma, é difícil desassociar a afirmação do narrador sobre Gabriel - "é chegado o momento para que ele iniciasse sua jornada rumo ao Oeste" (JOYCE, 1994, p. 121) ${ }^{17}$ - da descoberta ou aceitação de uma "outra" Irlanda, que é inevitavelmente parte tanto de Gabriel quanto de Joyce.

A simbologia para o oeste é ainda outra conexão de Joyce e a peça The Playboy of the Western World. Para Levenson (1994) o episódio em que os nacionalistas atacaram Synge é um marco de como a arte não consegue neutralidade em relação à historicidade e a política, e, em Joyce, essa noção causaria um conflito pessoal entre uma estética purificada e uma demanda cultural nacionalista da arte como partidária das lutas contra a dominação imperial. Como apontado, as Ilhas Aran se conectam diretamente com Synge e o nacionalismo e não coincidentemente a palavra pennyboy liga a figura lúbrica que Gabriel havia sido até então à Christy de The Playboy of the Western World. Ambos sendo conduzidos pelas cordas invisíveis de sua audiência, tentando ser um "arremedo de herói".

and feels generosity to his wife, Gabriel is interesting and significant because he has the potential for growth and transformation.

17 JOYCE, 1994, p. 152. The time had come for him to set out on his journey westward. 


\section{Revista InterteXto / ISSN: 1981-0601}

$$
\text { v. 8, n. } 1 \text { (2015) }
$$

Conclui-se que, ainda que James Joyce estivesse distanciado de seus contemporâneos nacionalistas na escolha temática das histórias de Dubliners, retratando com minúcia o cotidiano burguês da classe média irlandesa, em detrimento de uma observação do "rico imaginário popular" (SYNGE, 1993, p.6) dos camponeses irlandeses, o conto "The Dead" não se abstém de um diálogo ainda que implícito com a produção nacionalista, neste caso em especial, com a peça The Playboy of the Western World escrita por seu contemporâneo Synge. Demonstramos através deste artigo, os pontos de encontro entre as duas obras, e como o episódio vivido por Synge no importante Abbey Theater reverbera no último dos quinze contos de Dubliners.

\section{REFERÊNCIAS:}

BACKUS Margot G. Sexual Figures of National Identity in "The Dead." em

GILLERSPIE Michael P. (ed) James Joyce and the fabrication of an Irish identity. European Joyce's Studies, s.l: Editions Rodopi, 2001, p.p. 111-13.

EAGLETON, Terry. The English Novel: An Introduction. Oxford: Blackwell Publsihing, 2005.

ELLMANN, Richard. James Joyce. Rev. ed. New York: Oxford UP, 1982.

ELLSWORTH, Mason. ELLMANN, Richard. The Critical Writings Of James Joyce (New York: Viking, 1959); em JOYCE, James. The Dead (Edited by Daniel R. Schwarz).Boston: Bedford Books of St. Martin's Press, 1994, p.162.

FRIEDRICH, Gerhard. The Perspective of Joyce's Dubliners. College English, Vol. 26, $n^{\circ} 6$, National Council of Teachers of English, 1965, p.p. 421-426.

HIRSCH, Edward. The Imaginary Irish Peasant. PMLA, Vol. 106, no. 5. Modern Language Association, 1991, p.p. 1116-1133.

JOYCE, James. Dublinenses. BRAGA, Guilherme da Silva.(trad.) Porto Alegre: L\&PM Pocket; 2012.

JOYCE, James. Dubliners. New York: Dover Publications, Inc; 1991. 
JOYCE, James. The Dead. SCHWARZ Daniel R. (ed.) Boston: Bedford Books of St. Martin's Press, 1994, p.p. 21-59.

KIBERD, Daclan. 'A Faker of Peasant Speech'?. The Review of English Studies, New Series, Vol. 30, nº 117, Oxford University Press, 1979, p.p. 59-63.

LEVENSON, Michael. Living History in "The Dead" em em JOYCE, James. The Dead. SCHWARZ Daniel R. (ed.) Boston: Bedford Books of St. Martin's Press, 1994, p.p. 163177.

LIMA, Geraldo F. Abbey theater: um dramaturgo encontra o seu caminho. Sitientibus, Feira de Santana, $n^{\circ}$ 18, jan./jun 1998, p.p. 143-166.

LIMA, Geraldo F. Aran: a descoberta de um dramaturgo. Sitientibus, Feira de Santana, no 16, jan./jun 1997, p.p.97-113.

NORRIS, Margot. Not the Girl She Was at All: Women in "The Dead" em JOYCE, James. The Dead. SCHWARZ Daniel R. (ed.) Boston: Bedford Books of St. Martin's Press, 1994, p.p. 190-205.

ROSS, Bonnie. "James Joyce's 'The Dead" and Bret Harte's Gabriel Conroy: The Nature of the Feast" in Yale Journal of Criticism, vol. 15, n¹, 2002, p.p. 99-126.

SCHWARZ, Daniel R. Gabriel Conroy's Psyche: Character as Concept em JOYCE, James. The Dead. SCHWARZ Daniel R. (ed.) Boston: Bedford Books of St. Martin's Press, 1994, p.p. 102-124.

SCHWARZ, Daniel R. Introduction: Biographical and Historical Contexts em JOYCE, James. The Dead. SCHWARZ Daniel R. (ed.) Boston: Bedford Books of St. Martin's Press, 1994, p. 3-20.

SYNGE, J. M. The Playboy of the Western World and Riders to the Sea. SMITH, Philip. (ed.) New York: Dover, Inc., 1993.

Artigo recebido em 28/02/2015

Artigo aceito em 20/03/2016 